\title{
Amélia Neves de Souto, Caetano e o Ocaso do "Império". Administração e Guerra Colonial em Moçambique durante o Marcelismo (1968-1974), Porto, Edições Afrontamento, 2007, 453 p., cartes noir et blanc et couleur, ISBN : 978-972-36-0933-2.
}

Cette thèse de doctorat en histoire institutionnelle et politique des $\mathrm{xIX}-\mathrm{Xx}^{\mathrm{e}}$ siècles, soutenue en 2003 à l'Universidade Nova de Lisbonne, est importante et ambitieuse. Trop ambitieuse même, si l'on veut caser en 453 p. tous les sujets énumérés dans la table des matières. On en citera quelques-uns, ci-après : législation, administration, économie, peuplement blanc, autorités civiles, pouvoir militaire, liaisons et tiraillements entre les deux branches du commandement, services de renseignement, action psychologique, le Frelimo, populations africaines, stratégie portugaise, principales opérations, rivalités Armée-DGS (ex-Pide), africanisation des troupes, relations tendues ou «apaisées » avec la Tanzanie, la Zambie, le Malawi, la Rhodésie, l'Afrique du Sud, opposition blanche antisalazariste, position des Églises, sectes nativistes, etc. Inévitablement, certains thèmes sont justes esquissés et, en fait, malgré le titre, Caetano est loin d'être l'acteur principal dans toutes les rubriques. L'auteure ne cache nullement sa pensée. Pour elle, Caetano n'est pas seulement l'héritier de Salazar. C'est son complice dans la définition et la conduite de la politique coloniale: un orthodoxe et non un rénovateur, malgré les apparences qu'il cultivait dans l'ambiguïté.

Victime de la légendaire, de l'incroyable carence en livres étrangers des bibliothèques publiques lusophones, la bibliographie utilisée est inégale, pour ne pas dire trop souvent lacunaire. Naïvement, nous pensions qu'aux Archives de Maputo leur première Directrice avait déjoué cette malédiction. Or nous constatons que sont absents de ce travail presque tous les innombrables témoignages (mémoires ou plaidoyers, voire romans) des militaires portugais. On ne relève qu'un seul texte de Kaulza de Arriaga et pas le plus important. On cherche désespérément des écrits de pasteurs ou de missionnaires catholiques "importés » qui, en leur temps, firent quelque bruit. Des reportages pro-Frelimo ou procolonialistes devenus classiques sont laissés de côté. À quoi bon allonger cette liste? En revanche, et c'est là que réside la grande utilité du livre, l'ouvrage est fondé essentiellement sur le dépouillement des archives accessibles au Mozambique et au Portugal (pas l'Arquivo Histórico Ultramarino, naturellement, mais celles du ministère des Affaires étrangères et surtout des autorités militaires). À cela, s'ajoutent des interviews avec des protagonistes importants et une lecture attentive de la presse locale et portugaise (ici, simples sondages ponctuels).

Dans ce terrain peu défriché scientifiquement, l'auteure nous livre donc sans mal une brochette de faits inconnus de la plupart de ses lecteurs, et parfois des perles rares. Citons, entre autres, la dénonciation par la Pide de la brutalité des milices commandées par le « célèbre » condottiere Daniel Roxo (1965) actuellement en cours de «béatification » par certains retornados nostalgiques. Ajoutons les réticences et l'opposition de Kaulza de Arriaga, face aux demandes d'intervention militaire des Rhodésiens dans le distrito de Tete pour pallier l'incapacité de ses troupes. Plus dangereux à long terme pour l'avenir de la présence portugaise dans cette colonie que ce stratège en peau de banane prétendait "pacifier » à lui seul, 
l'auteure est la première, semble-t-il, à documenter de l'intérieur les vives tensions entre les Sud-Africains et le haut-commandement portugais qu'ils accusent d'impuissance et d'incompétence.

Bref, cette thèse hybride détruit bon nombre de clichés qui ont encore la vie dure dans certains secteurs des opinions publiques portugaises ou mozambicaines lesquels, faute de victoires plus incontestables, entretiennent d'anciens ou de nouveaux mythes consolateurs et même thérapeutiques. Neves de Souto n'est pas pour ces médecines douces. Elle a raison probablement. Elle ouvre les abcès.

Novembre 2008, René Pélissier

\section{Nuno Vidal \& Justino Pinto de Andrade (eds), Sociedade civil e política em Angola. Enquadramento regional e internacional, Lisbonne, Edições} Firmamento - Media XXI/Luanda, Adra Angola, 2e éd., 2009, xxxiii + 403 p., ISBN : 972-992-704-9.

Même si l'on «oublie» la partie consacrée aux autres pays d'Afrique australe (dont le Mozambique), qui représente presque une centaine de pages, ce livre important met le recenseur dans l'incertitude et l'embarras. Il ne sait comment concilier, d'une part, l'identité de certains des organismes qui le financent (Universidade Cátolica de Angola, Comunidade dos Países de Lingua Portuguesa, Acção para o Desenvolvimento Rural e Ambiente: ADRA-Angola, Open Society Foundation-Angola, pour se limiter à ceux qui sont installés en Angola ou le représentent) et, d'autre part, la virulence des critiques qui sont adressées au pouvoir en place. De quatre choses l'une. Ou ceux qui ont décidé qu'ils pouvaient patronner sa publication n'ont pas lu tous les textes qu'il contient, ou les Angolais lettrés jouissent d'une liberté d'opinion et d'expression contredisant la féroce diabolisation de ceux que trois auteurs néerlandais désignent comme «les sphinx de Futungo» (p. 258), ou ils brûlent leurs vaisseaux et, coûte que coûte, sont prêts à braver leur vengeance, ou alors ils se sentent intouchables.

Quoi qu'il en soit, la force et la pertinence des attaques que la bonne quinzaine d'Angolais vivant in situ décochent à leurs politiciens ne sont pas contestables. On croyait ces philippiques réservées aux grincheux, aux atrabilaires et autres opposants en exil qu'engendre toute dictature digne de ce nom. En fait, on s'aperçoit vite que la plupart dépendent d'ONG internationales ou locales, ce qui nous pousse à croire que ces dernières ont acquis assez de poids pour oser contester de l'intérieur les agissements de leurs gouvernants. G'est socialement et économiquement assez courageux dans un pays où près des trois quarts des emplois dans le secteur formel sont fournis par l'État. Il serait d'ailleurs intéressant de savoir si cette pugnacité est antérieure à la fin de la guerre civile ou si la cessation de la répression des bavards a ouvert les vannes d'une longtemps impuissante colère contre le MPLA, parmi les élites qui voudraient se substituer à ses vieux et jeunes crocodiles et à leurs affidés.

En tout cas, comme dans toute bonne pétrocratie qui se respecte, greed is good en Angola et même, pour certains, greed is God. Dès 2003, avant donc la mise en exploitation de nouveaux blocs pétrolifères, un journal de Luanda, O Angolense, 